\title{
Antiepileptic drugs and vitamin B6 plasma levels in adult patients
}

\author{
Linnebank, M ; Moskau, S ; Semmler, A ; Widman, G ; Weller, M ; Kallweit, U ; Elger, C E
}

\begin{abstract}
Treatment with several antiepileptic drugs (AED) is associated with lower serum concentrations of folate or vitamin B12. This prospective monocenter study analyzed vitamin B6 blood levels in 400 serial patients with epilepsy, AED-treated $(n=385)$, untreated $(n=15)$ and healthy controls $(n=233)$. The mean plasma vitamin B6 levels of the AED-treated (12.1 $\pm 10.1 ; \mathrm{p}=0.093)$ and the untreated patients $(15.6 \pm 12.4 ; \mathrm{p}=0.664)$ were not significantly different from the controls $(13.9 \pm 15.2)$. These observations do not support the hypothesis that vitamin B6 blood levels are influenced by AED treatment.
\end{abstract}

DOI: https://doi.org/10.1016/j.eplepsyres.2012.03.002

Posted at the Zurich Open Repository and Archive, University of Zurich

ZORA URL: https://doi.org/10.5167/uzh-64664

Journal Article

Accepted Version

Originally published at:

Linnebank, M; Moskau, S; Semmler, A; Widman, G; Weller, M; Kallweit, U; Elger, C E (2012). Antiepileptic drugs and vitamin B6 plasma levels in adult patients. Epilepsy Research, 101(1-2):182-184.

DOI: https://doi.org/10.1016/j.eplepsyres.2012.03.002 


\section{Antiepileptic drugs and vitamin B6 plasma levels}

Michael Linnebank ${ }^{1,2}$, Susanna Moskau ${ }^{3}$, Alexander Semmler ${ }^{1}$, Guido Widman ${ }^{3}$, Michael Weller ${ }^{1}$, Christian E. Elger ${ }^{3}$

${ }^{1}$ Department of Neurology, University Hospital Zurich, Switzerland

${ }^{2}$ Department of Neurology, University Hospital Bonn, Germany

${ }^{3}$ Department of Epileptology, University Hospital Bonn, Germany

\section{Correspondence}

PD Dr. Michael Linnebank, Department of Neurology, University Hospital Zurich,

Frauenklinikstrasse 26, CH-8091 Zurich, Switzerland. Phone: 004144 2551111. Fax: 004144 2554507. E-mail: michael.linnebank@usz.ch

Prof. Dr. Christian E. Elger, Department of Epileptology, University Hospital Bonn, Sigmund-Freud-Str. 25, D-53105 Bonn, Germany. Phone: 0049228 28715727. Fax: 0049228 28714328. E-mail : christian.elger@ukb.uni-bonn.de

\section{$\underline{\text { Acknowledgements }}$}

This study was supported by a local Bonfor grant (ML). 


\begin{abstract}
Treatment with several antiepileptic drugs (AED) is associated with lower serum concentrations of folate or vitamin B12. Several small studies suggest that AED treatment may also interfere with vitamin B6 plasma levels. This prospective monocenter study analyzed vitamin B6 blood levels in 400 serial patients with epilepsy, AED-treated $(n=385)$ or untreated $(\mathrm{n}=15)$. As healthy local controls, 233 age- and gender-matched blood donors were analyzed. Individuals supplementing vitamin B6 were not eligible.

The mean plasma vitamin B6 levels $(\mu \mathrm{g} / \mathrm{ml} \pm 1$ standard deviation, $\mathrm{SD})$ of the AED-treated $(12.1 \pm 10.1 ; \mathrm{F}=2.84 ; \mathrm{p}=0.093)$ and the untreated patients $(15.6 \pm 12.4 ; \mathrm{F}=0.19 ; \mathrm{p}=0.664)$ were not significantly different from the controls $(13.9 \pm 15.2)$ tested by ANOVA. Accordingly, the frequency of vitamin B6 plasma levels below the reference range $(5 \mu \mathrm{g} / \mathrm{ml})$ of the AED-treated $(0.12 ; \mathrm{Chi}=0.02 ; \mathrm{p}=0.882)$ and the untreated patients $(0.13 ; \mathrm{Chi}=0.01$; $\mathrm{p}=0.959)$ did not significantly differ from the controls $\left(0.13\right.$; Pearson's $\left.\mathrm{Chi}^{2}\right)$. Explorative subgroup analysis did not reveal that single AED were associated with vitamin B6 mean plasma levels or levels below the reference range both in poly- or monotherapies. In patients with vitamin B6 plasma levels below the reference range, oral substitution with $20 \mathrm{mg}$ per day lead to reconstitution of the plasma levels. These observations do not support the hypothesis that vitamin B6 blood levels are influenced by AED treatment.
\end{abstract}




\section{Objective}

Treatment with several of the commonly used antiepileptic drugs (AED) is associated with lower folate or vitamin B12 serum levels (Linnebank, et al. 2011). Although reports have remained controversial, several studies have also suggested decreased vitamin B6 plasma levels in association with treatment with carbamazepine $n=20$ patients (Attilakos, et al. 2006), $\mathrm{n}=19$ (Sener, et al. 2006), $\mathrm{n}=28$ (Verrotti, et al. 2000), $\mathrm{n}=20$ (Tamura, et al. 2000), phenytoin $n=20$ (Tamura, et al. 2000), valproate $n=13$ (Tamura, et al. 2000), $n=32$ (Verrotti, et al. 2000) or with any AED treatment $n=101$ (Apeland, et al. 2003), $n=500$ (Krause, et al. 1988), $\mathrm{n}=51$ (Schwaninger, et al. 1999), $\mathrm{n}=59$ (Vilaseca, et al. 2000). Major et al. suggested that substitution of vitamin B6 lowered behavioral side effects of levetiracetam in 42 pediatric patients (Major, et al. 2008).

Vitamin B6, in its active form, is necessary for numerous amino acid transformation reactions. In the brain, the synthetic pathways for dopamine, noradrenaline and 5hydroxytryptamine contain enzymes that require vitamin B6 for their function. Further, both glutamate decarboxylase and $\gamma$-aminobutyrate (GABA) aminotransferase, the enzymes of GABA synthesis and degradation, employ vitamin B6 for their catalytic mechanisms (Tunnicliff 1986, Tunnicliff, et al. 1986).

In summary, AED treatment may compromise vitamin B6 plasma levels and thereby different pathways of human metabolism, e.g. neurotransmitter synthesis and degeneration. However, the available epidemiological studies are small or analyzed only older AED. In the present study, plasma vitamin B6 levels were analyzed in 400 patients with epilepsy and in 233 healthy controls. 


\section{Methods}

This prospective study included serial in- and out-patients of the Department for Epileptology of the University Hospital Bonn, Germany, who suffered from epilepsy. Period of recruitment was November and December 2006. Patients with epilepsy treated with the therapy when presenting at our hospital for at least three months were enrolled as AED-treated patients $(\mathrm{n}=$ 385 , mean age $(y) \pm 1$ standard deviation $(S D)=38 \pm 14$; ratio female: 0.49$)$. Patients not treated with any AED for at least three months were enrolled as untreated patients $(n=15 ; 40$ \pm 19 y; 0.47 female). Patients were not eligible if they supplemented vitamin B6. Age- and gender-matched, but otherwise unselected 233 blood donors served as healthy local controls ( $n=233 ; 37 \pm 15 y ; 0.48$ female). The study was approved by the local ethics committee. Vitamin B6 was measured in plasma in the clinical routine. SPSS version 16 was used for statistical analysis (SPSS, Chicago, IL, USA). Pearson's Chi ${ }^{2}$ tests and univariate analysis of variance (ANOVA) were used for univariate analysis of numeric and metric data, respectively. For the analysis of associations with single AED and vitamin B6, only AED taken by at least 20 patients were analyzed. In total, 177 of the 385 patients (46\%) were treated with monotherapies. 


\section{Results and discussion}

None of the analyzed AED was associated with mean vitamin B6 plasma levels or with the frequency of vitamin B6 plasma levels below the reference range. Accordingly, untreated patients showed no differences compared with treated patients (table 1). Results did not differ if only patients treated with AED monotherapy were analyzed (not shown). In total, 48 (12\%) of the patients had vitamin B6 plasma levels below the reference range. None of these individuals was pregnant. All were offered to supplement vitamin B6. Because of the unknown biological relevance of vitamin B6 levels below the laboratory reference range, only 32 patients decided to start therapy. Initially, we advised $100 \mathrm{mg}$ per os per day as approved for oral therapy of vitamin B6 deficiency, but three patients claimed newly evolved disturbances of sensibility compatible with peripheral sensory neuropathy as known as possible side effect of vitamin B6. Therefore, we only substituted 20mg thereafter. With this regimen, vitamin B6 plasma levels became reconstituted in all individuals, and no signs of neuropathy were reported or detected in follow-up examinations. Although not studied in a standardized manner, we did not observe any improvement, nor deterioration, of seizure frequency or neurological findings related to vitamin B6 substitution in follow-up examinations. These observations do not support the hypothesis that vitamin B6 blood levels are influenced by AED treatment. Consequently, the present study does not suggest that vitamin B6 blood levels should be monitored in patients treated with AED or that this vitamin should prophylactically substituted in respective individuals. Thirteen percent of the healthy controls and $12 \%$ of the patients had vitamin B6 blood levels below the reference questioning the accuracy of the applied reference range. Larger studies should be performed to generate valid reference data. If vitamin B6 is to be substituted, 20mg/ day per os may be chosen, which has been safe and sufficient in our study. 
We confirm that we have read the Journal's position on issues involved in ethical publication and affirm that this report is consistent with those guidelines.

\section{Disclosure}

ML is member of the D.A.CH.-Liga homocysteine which is sponsored by companies that sell vitamin products. The remaining authors have no conflicts of interest.

\section{References}

Apeland T, Mansoor MA, Pentieva K, McNulty H, Strandjord RE. (2003) Fasting and postmethionine loading concentrations of homocysteine, vitamin B2, and vitamin B6 in patients on antiepileptic drugs. Clin Chem 49:1005-1008.

Attilakos A, Papakonstantinou E, Schulpis K, Voudris K, Katsarou E, Mastroyianni S, Garoufi A. (2006) Early effect of sodium valproate and carbamazepine monotherapy on homocysteine metabolism in children with epilepsy. Epilepsy Res 71:229-232.

Krause KH, Bonjour JP, Berlit P, Kynast G, Schmidt-Gayk H, Schellenberg B. (1988) Effect of long-term treatment with antiepileptic drugs on the vitamin status. Drug Nutr Interact 5:317-343.

Linnebank M, Moskau S, Semmler A, Widman G, Stoffel-Wagner B, Weller M, Elger CE. (2011) Antiepileptic drugs interact with folate and vitamin B12 serum levels. Ann Neurol. 
Major P, Greenberg E, Khan A, Thiele EA. (2008) Pyridoxine supplementation for the treatment of levetiracetam-induced behavior side effects in children: preliminary results. Epilepsy Behav 13:557-559.

Schwaninger M, Ringleb P, Winter R, Kohl B, Fiehn W, Rieser PA, Walter-Sack I. (1999) Elevated plasma concentrations of homocysteine in antiepileptic drug treatment. Epilepsia 40:345-350.

Sener U, Zorlu Y, Karaguzel O, Ozdamar O, Coker I, Topbas M. (2006) Effects of common anti-epileptic drug monotherapy on serum levels of homocysteine, vitamin B12, folic acid and vitamin B6. Seizure 15:79-85.

Tamura T, Aiso K, Johnston KE, Black L, Faught E. (2000) Homocysteine, folate, vitamin B12 and vitamin B-6 in patients receiving antiepileptic drug monotherapy. Epilepsy Res 40:7-15.

Tunnicliff G. (1986) 4-Aminobutyrate transaminase. In Boulton AAB, G.B.; Yu, P.H., (Ed) Neuromethods. 5 - Neurotransmitter encymes. Humana Press, pp. 389-419.

Tunnicliff G, Ngo TT. (1986) Regulation of ?-aminobutyric acid synthesis in the vertebrate nervous system. Neurochem Int 8:287-297.

Verrotti A, Pascarella R, Trotta D, Giuva T, Morgese G, Chiarelli F. (2000) Hyperhomocysteinemia in children treated with sodium valproate and carbamazepine. Epilepsy Res 41:253-257.

Vilaseca MA, Monros E, Artuch R, Colome C, Farre C, Valls C, Cardo E, Pineda M. (2000) Anti-epileptic drug treatment in children: hyperhomocysteinaemia, B-vitamins and the 677C--> T mutation of the methylenetetrahydrofolate reductase gene. Eur J Paediatr Neurol 4:269-277. 
Table 1: Vitamin B6 plasma levels

\begin{tabular}{|c|c|c|c|c|}
\hline & \\
\hline & $\begin{array}{l}\text { Mean plasma levels } \\
(\mu \mathrm{g} / \mathrm{ml}) \pm \mathrm{SD}\end{array}$ & vs healthy controls & $\begin{array}{l}\text { Frequency of } \\
\text { subnormal levels }\end{array}$ & vs healthy controls \\
\hline Healthy controls $(n=233)$ & $13.9 \pm 15.2$ & -- & 0.13 & -- \\
\hline All AED-treated patients $(n=385)$ & $12.1 \pm 10.1$ & $\mathrm{~F}=2.84 ; \mathrm{p}=0.093$ & 0.12 & Chi $=0.02 ; p=0.882$ \\
\hline Untreated patients $(\mathrm{n}=15)$ & $15.6 \pm 12.4$ & $\mathrm{~F}=0.19 ; \mathrm{p}=0.664$ & 0.13 & $\mathrm{Ch}=0.01 ; \mathrm{p}=0.959$ \\
\hline Clobazam $(n=33)$ & $12.1 \pm 10.2$ & $F=0.41 ; p=0.525$ & 0.15 & Chi $=0.13 ; p=0.717$ \\
\hline Carbamazepine $(\mathrm{n}=80)$ & $14.9 \pm 15.6$ & $F=0.28 ; p=0.595$ & 0.15 & Chi $=0.23 ; p=0.631$ \\
\hline Lamotrigine $(\mathrm{n}=125)$ & $12.2 \pm 8.8$ & $\mathrm{~F}=1.22 ; \mathrm{p}=0.271$ & 0.15 & Chi $=0.372 ; p=0.324$ \\
\hline Levetiracetam $(\mathrm{n}=120)$ & $11.1 \pm 7.9$ & $\mathrm{~F}=3.55 ; \mathrm{p}=0.060$ & 0.13 & Chi $=0.10 ; p=0.920$ \\
\hline Oxcarbazepine $(\mathrm{n}=49)$ & $11.1 \pm 8.9$ & $\mathrm{~F}=1.49 ; \mathrm{p}=0.223$ & 0.16 & Chi $=0.41 ; p=0.520$ \\
\hline Phenobarbital $(\mathrm{n}=32)$ & $11.3 \pm 7.8$ & $\mathrm{~F}=0.86 ; \mathrm{p}=0.355$ & 0.16 & Chi $=0.19 ; p=0.667$ \\
\hline Phenytoin $(\mathrm{n}=25)$ & $8.7 \pm 4.0$ & $\mathrm{~F}=2.81 ; \mathrm{p}=0.095$ & 0.20 & Chi $=0.98 ; p=0.323$ \\
\hline Pregabalin $(n=39)$ & $10.8 \pm 6.6$ & $\mathrm{~F}=1.57 ; \mathrm{p}=0.211$ & 0.10 & Chi $=0.21 ; p=0.647$ \\
\hline Topiramate $(n=36)$ & $11.1 \pm 8.9$ & $F=1.13 ; p=0.289$ & 0.14 & Chi $=0.03 ; p=0.866$ \\
\hline Valproate $(\mathrm{n}=103)$ & $10.9 \pm 7.9$ & $F=3.46 ; p=0.064$ & 0.15 & Chi $=0.18 ; p=0.675$ \\
\hline
\end{tabular}


